\title{
A seção-tipo da Formação Serra do Quilombo, Grupo Araras, Neoproterozoico da Faixa Paraguai Norte, Mato Grosso
}

The type section of Serra do Quilombo Formation, Neoproterozoic Araras Group, Northern Paraguay Belt, state of Mato Grosso

\author{
João Marinho Milhomem Neto ${ }^{1 *}$, Afonso César Rodrigues Nogueira2 ${ }^{2}$ \\ Moacir José Buenano Macambira ${ }^{2}$
}

\begin{abstract}
RESUMO: Após a última glaciação criogeniana ( $c a .635 \mathrm{Ma}$ ), extensas plataformas carbonáticas desenvolveram-se sobre diversas regiōes cratônicas da Terra e, apesar da intensa dolomitização desses depósitos, muitas informaçōes paleoambientais e paleoceanográficas estão preservadas. Um dos exemplos mais importantes deste período no Brasil são os dolomitos da Formaçáo Serra do Quilombo, pertencente à porção superior do Grupo Araras, no segmento norte da Faixa Paraguai, sul do Cráton Amazônico. A reavaliaçấo estratigráfica da seçâo-tipo da formaçấo e de uma seção de referência na região de Nobres, com base na análise de fácies e estratigráfica, permitiu ampliar as interpretaçôes paleoambientais e elaborar um modelo deposicional. A sucessão estudada, de $140 \mathrm{~m}$ de espessura, inclui a Formação Serra do Quilombo em contato basal brusco com os calcários da Formação Guia e a passagem gradual para os dolomitos arenosos da Formação Nobres, no topo. A Formação Serra do Quilombo representa um megaciclo de raseamento ascendente, constituído por duas associaçóes de fácies: 1) plataforma carbonática profunda à moderadamente rasa, composta por um dolomito fino laminado rico em matéria orgânica e outro maciço a laminado; e 2) face litorânea influenciada por tempestades, constituída por dolomito arenoso com estratificaçáo cruzada hummocky/swaley associada com estratificação plano-paralela, dolomito arenoso/oolítico com laminaçóes produzidas por ondas e brecha dolomítica com matriz. A Formaçăo Serra do Quilombo representa o registro progradante de um trato do sistema de mar alto, em um contexto de rampa carbonática homoclinal instalada no sul do Cráton Amazônico durante o Ediacarano.
\end{abstract}

PALAVRAS-CHAVE: fácies carbonáticas; Formação Serra do Quilombo; Faixa Paraguai Norte; Ediacarano.

\begin{abstract}
After the last Cryogenian glaciation (ca.635 Ma), large carbonate platforms were developed in several cratonic regions of the Earth and, despite the intense dolomitization of these deposits, paleoceanographic and paleoenvironmental pieces of information are preserved. One of the most important examples of this period in Brazil are the dolostones of Serra do Quilombo Formation, which belong to the upper portion of the Araras Group, exposed in the northern Paraguay Belt, south of the Amazonian Craton. The stratigraphic revaluation of this formation in its type-section and in a reference section in the Nobres region, based on facies and stratigraphic analyses, allowed to enlarge the paleoenvironmental interpretations and to propose a depositional model. The study succession of $140 \mathrm{~m}$ thick includes Serra do Quilombo Formation in sharp basal contact with the limestones of Guia Formation and the gradual contact, to the top, with the sandy dolostones of Nobres Formation, at the top. Serra do Quilombo Formation comprises a shallowing upward succession, which includes two facies associations: 1) deep to moderately shallow carbonate platform, composed of laminated dolostone rich in organic matter and a massive to laminated dolostone; and 2) storm influenced shoreface, consisting of hummocky/swaley to planar stratified sandy dolostone, sandy/oolitic dolostone with wave cross laminations and matrix-supported dolomitic breccias. Serra do Quilombo Formation represents the progradational record of a high-stand system tract, in a homoclinal carbonate ramp, installed on the southern part of the Amazonian Craton during the Ediacaran.
\end{abstract}

KEYWORDS: carbonate facies; Serra do Quilombo Formation; Northern Paraguay Belt; Ediacaran.

\footnotetext{
${ }^{1}$ Programa de Pós-Graduação em Geologia e Geoquímica, Instituto de Geociências, Universidade Federal do Pará - UFPA, Belém (PA), Brasil. E-mail: milhomem@ufpa.br ${ }_{2}^{2}$ Instituto de Geociências, Faculdade de Geologia, Universidade Federal do Pará - UFPA, Belém (PA), Brasil. E-mail: anogueira@ufpa.br; moamac@ufpa.br Manuscrito ID 26561. Recebido em: 13/04/2012. Aprovado em: 22/04/2013
} 


\section{INTRODUÇÃO}

Extensas plataformas carbonáticas desenvolveram-se sobre diversas regióes cratônicas da Terra, recobrindo depósitos glaciais correlatos à última glaciação global criogeniana ( $C a$. $635 \mathrm{Ma}$ ) e formando uma sequência sedimentar que sustenta as teorias de congelamento total ou parcial do Planeta naquele período, em inglês "snowball/ slushball Earth hypothesis" (Hoffman \& Schrag 2002, Allen \& Hoffman 2005, Nogueira et al. 2007). Apesar da intensa dolomitização de parte de tais depósitos carbonáticos, muitos dos processos sedimentares e paleoceanográficos podem ainda ser desvendados, contribuindo para o entendimento paleoambiental durante o final do Neoproterozoico. No Brasil, um dos mais importantes exemplos deste período são os dolomitos e as brechas da Formação Serra do Quilombo, incluída na sucessão carbonática do Grupo Araras (Nogueira et al. 2003, 2007), exposta no segmento norte da Faixa Paraguai, sul do Cráton Amazônico (Fig. 1). O Grupo Araras é constituído, da base para o topo, pelas formaçôes Mirassol d'Oeste (dolomitos e estromatólitos), Guia (calcários e folhelhos betuminosos), Serra do Quilombo (brechas dolomíticas e dolomitos) e Nobres (dolomitos e arenitos), relacionadas aos depósitos de plataforma e costeiros (Nogueira et al. 2003, 2007).

A Formação Serra do Quilombo, descrita e individualizada formalmente por Nogueira (2003), é composta basicamente por dolomitos e brechas dolomíticas e tem sido interpretada, em sua seção-tipo na regiáo de Cáceres, estado do Mato Grosso, como representante dos depósitos de uma plataforma moderadamente rasa à profunda, influenciada por sismos e tempestades (Nogueira \& Riccomini 2006). Suas melhores exposiçôes, na regiāo de Cáceres, encontram-se na frente de lavra da empresa Emal-Camil (Figs. 1 a 3), porção SE da Serra do Quilombo, considerada como holoestratótipo da unidade (Nogueira \& Riccomini 2006). Diversos outros afloramentos ocorrem ao longo da Faixa Paraguai Norte, como, por exemplo, na região de Nobres (MT), indicando sua continuidade por centenas de quilômetros. Embora as interpretaçóes paleoambientais para esta unidade estejam em grande parte definidas em sua seção-tipo (Mina dolomítica Emal-Camil, Fig. 1), buscou-se, neste trabalho, a partir da análise de fácies e estratigráfica, reavaliá-las e estendê-las para a região de Nobres, ampliando assim o conhecimento sobre os contextos paleoambiental e paleogeográfico da Plataforma Araras.

\section{MATERIAIS E MÉTODOS}

O estudo estratigráfico das rochas carbonáticas neoproterozoicas da Formação Serra do Quilombo foi baseado nas técnicas de modelamento e análises de fácies de Walker (1992) e Kerans e Tinker (1997). Para tanto, foram selecionadas três seçóes expostas em cortes de lavra, nas regiôes de Cáceres e Nobres, situadas em flancos de dobras com mergulhos desde verticais a sub-horizontais, evitando-se repetiçóes de camadas e zonas com forte deformação tectônica. Análises petrográficas foram realizadas com vistas à caracterização das microfácies e à obtenção de informaçóes complementares para a interpretação paleoambiental, baseando-se nas classificaçóes de Dunham (1962), Folk (1959, 1962) e Wright (1992). As brechas carbonáticas foram descritas segundo os trabalhos de Laznicka (1988) e Bouchette et al. (2001). As 35 amostras analisadas foram coletadas sistematicamente de acordo com a individualização de fácies e levando-se em consideração a espessura da sucessão estudada, de modo a contemplá-la de forma homogênea (Fig. 2). A fim de auxiliar na diferenciação entre calcita e dolomita, todas as lâminas delgadas foram tingidas com Alizarina vermelha-S a uma concentraçáo de 0,2 g/100 mL de 1,5\% de ácido hidroclorídrico (Adams et al. 1984).

\section{SEGMENTO NORTE DA FAIXA PARAGUAI}

\section{Aspectos estruturais e evolutivos}

A faixa de dobramento Paraguai constitui um extenso orógeno Neoproterozoico, de aproximadamente $1.200 \mathrm{~km}$ de comprimento, que se estende, no Brasil, pelos estados de Mato Grosso e Mato Grosso do Sul. Sua evolução ocorreu às margens SSE do Cráton Amazônico e sua origem é resultante da convergência e colisão de três blocos continentais: Amazônia, São Francisco-Congo e Paraná ou Rio de La Plata, este coberto por rochas fanerozoicas da Bacia do Paraná (Almeida 1984, Trompette et al. 1998, Alkmin et al. 2001, Tohver et al. 2010). Esse evento de convergência foi atribuído à orogênese Brasiliana/Pan-Africana (600 a 490 Ma; Almeida 1984, Trompette 1994). A Faixa Paraguai tem sido considerada como um megagráben deformado durante a separação dos continentes Laurentia e Gondwana (Dalziel 1992), e como uma bacia foreland da Faixa Brasília (Trompette 1994, Trompette et al. 1998), que incluiria uma zona de deformação e cavalgamento e duas sub-bacias antefossa (foredeep) (Nogueira 2003).

De acordo com Souza (2012), a ausência de estruturas de colisão no segmento norte da Faixa Paraguai não permitiria enquadrar a Bacia Paraguai em um modelo foreland. Segundo ele, as rochas que a compóem seriam uma cobertura neoproterozoica-cambriana afetada por um evento rúptil tardio, de caráter transpressivo, como resultado da reativação de estruturas do Grupo Cuiabá, 


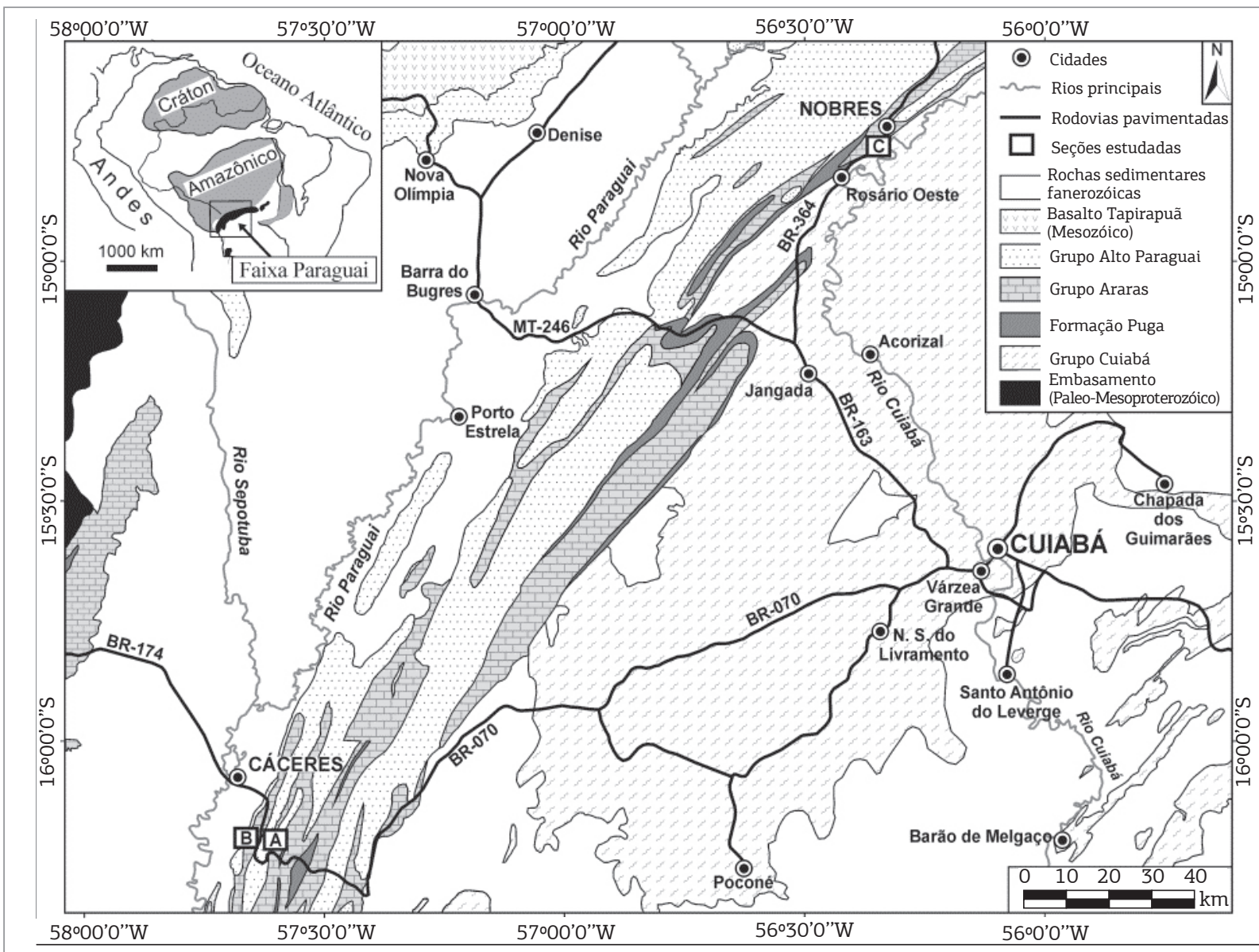

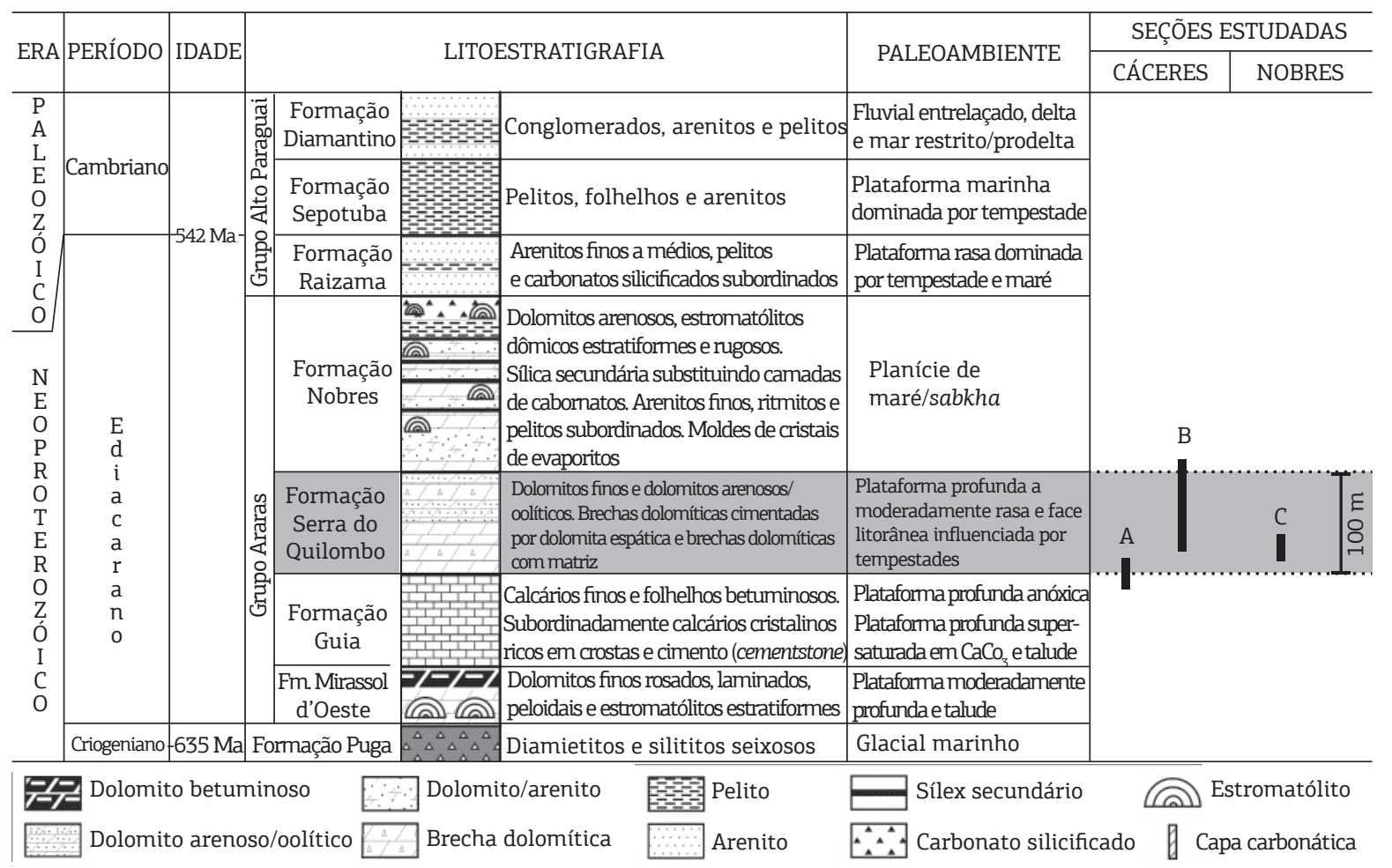

Localidades: A e B - Pedreiras Emal-Camil calcítica e dolomítica, respectivamente (km 707 da BR-070); C - mina inativa, 1 km a SW de Nobres. A escala ao lado dos perfis A, B e C é exclusiva para a espessura das seções estudadas.

Figura 1. Litoestratigrafia e contexto tectônico da Faixa Paraguai Norte (sul do Cráton Amazônico), com a localização das seções-alvos deste estudo (Modificado de Nogueira \& Riccomini 2006). 


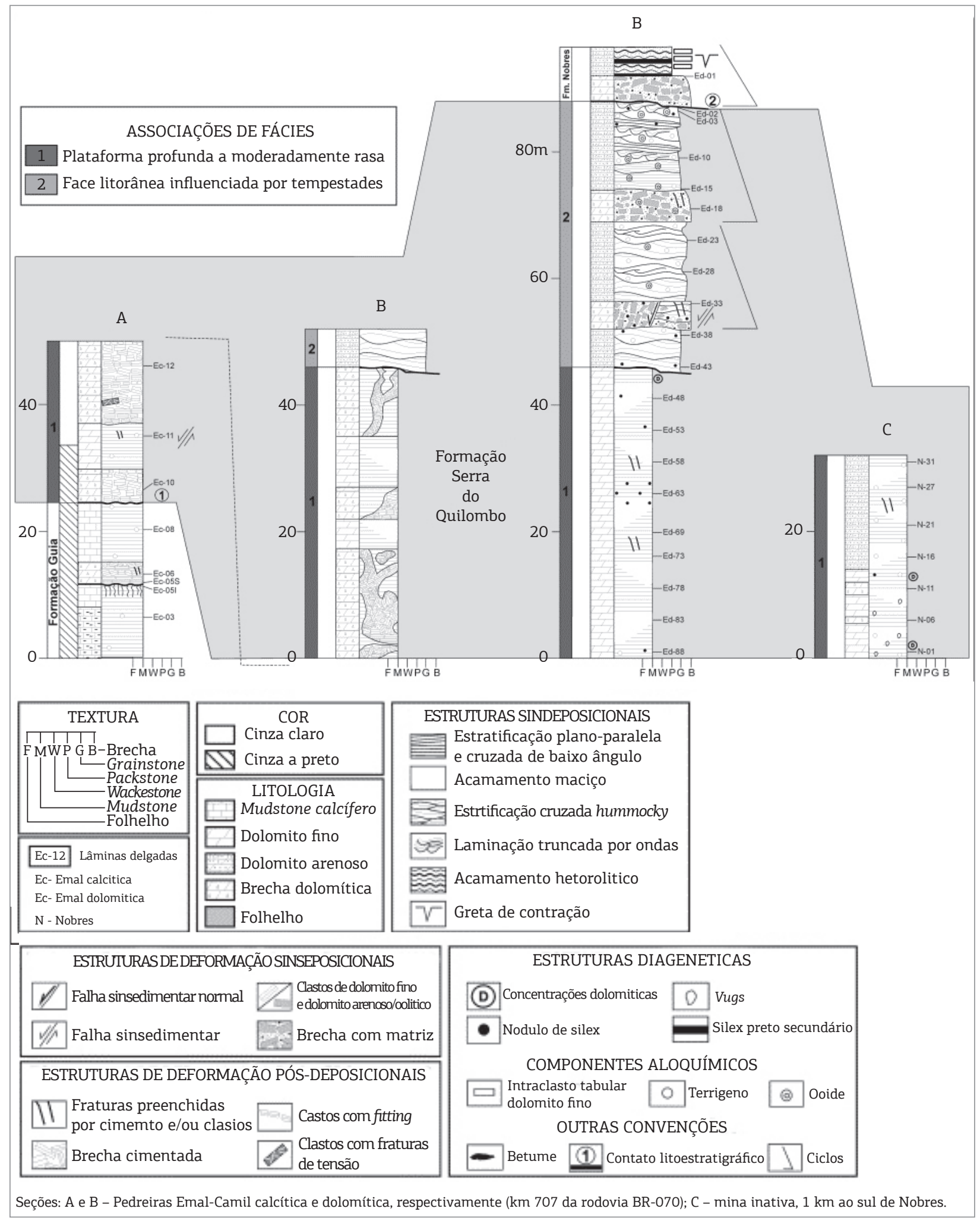

Figura 2. Perfis estratigráficos da Formação Serra do Quilombo.

embasamento da Bacia Paraguai, que representaria de fato a Faixa Paraguai, como resultado de um evento colisional ainda no Neoproterozoico. O último evento tectônico da orogênese Brasiliana/Pan-Africana (Almeida 1984) seria de idade eocambriana a ordoviciana (540 a $490 \mathrm{Ma})$ e teria ocorrido durante a Orogênese Paraguai (Basei \& Brito Neves 1992) ou Pampeana-Araguaia (Tohver et al. 2006, Rapela et al. 2007, Ramos et al. 2010), relacionado 

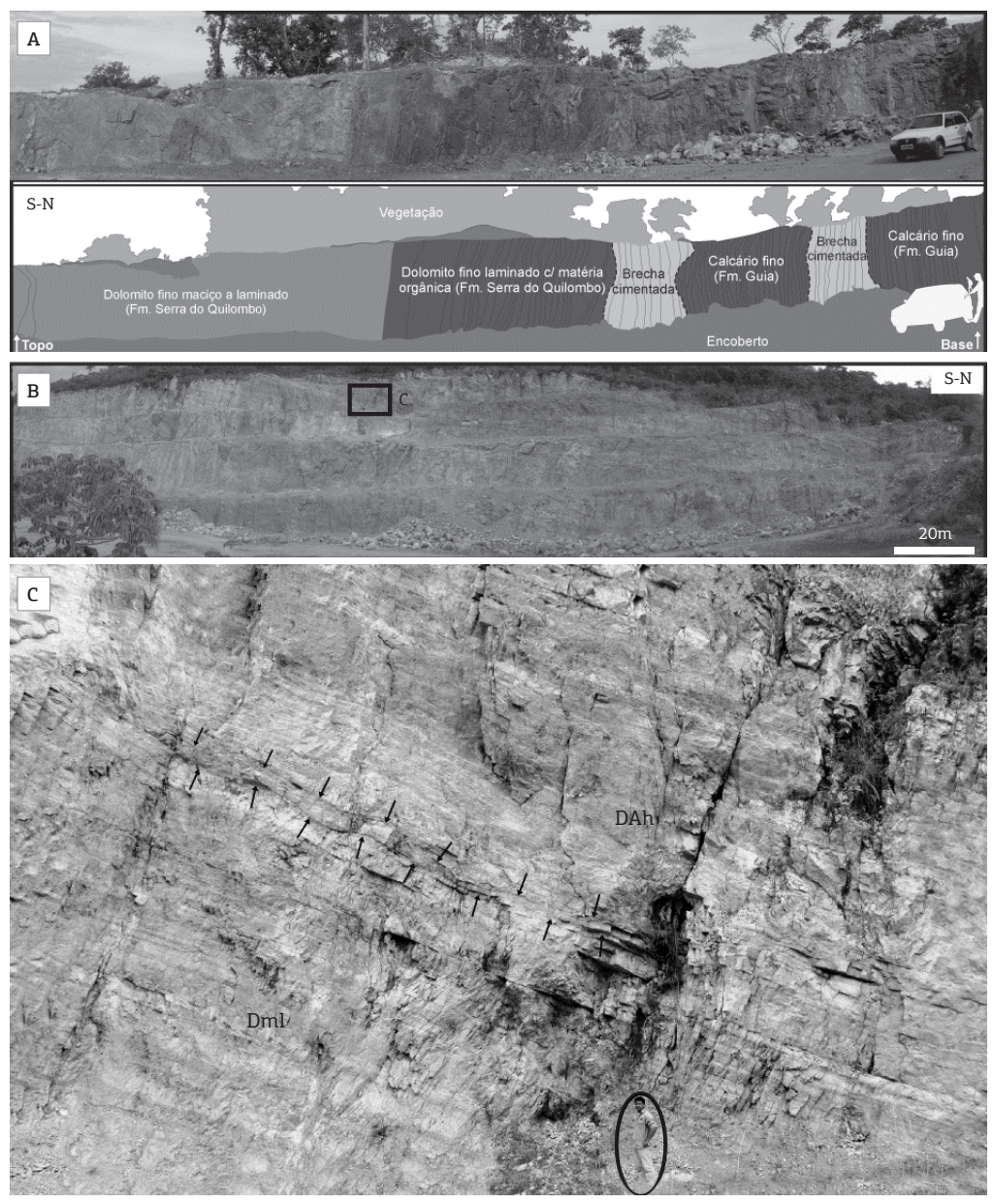

Figura 3. Seções panorâmicas das pedreiras estudadas. (A) Emal-Camil calcítica; (B) Emal-Camil dolomítica; (C) detalhe de $\mathrm{B}$ destacando os dolomitos arenosos com acamamento de megamarcas onduladas, setas (DAh) da associação de fácies 2 recobrindo os dolomitos finos maciços a laminados (Dml) da associação de fácies 1 .

ao fechamento do Oceano Clymene (Tohver et al. 2010). Eventos distensivos resultaram em intrusões graníticas com idade U-Pb de $518 \pm 4 \mathrm{Ma}$, fornecida pela datação do Granito São Vicente (McGee et al. 2011).

\section{Litoestratigrafia, paleoambiente e idade}

A litoestratigrafia da Faixa Paraguai Norte (Fig. 1) compreende o Grupo Cuiabá, que representa o embasamento da região, constituído por rochas pelíticas e camadas de quartzitos e calcários subordinados, metamorfisadas na fácies xisto-verde e intensamente dobradas (Almeida 1968). Sobre o embasamento estáo os diamictitos glaciogênicos da Formação Puga (Maciel 1959), correlatos à glaciação global do final do Criogeniano de ca. $635 \mathrm{Ma}$ (Nogueira et al. 2003 \& Alvarenga et al. 2004). Uma sucessão predominantemente carbonática, denominada Grupo Araras, recobre os diamictitos da Formação Puga. Tal grupo está exposto na margem sul-sudeste do Cráton Amazônico, principalmente na zona de cavalgamento e dobramento da parte norte da Faixa Paraguai (Almeida 1984), sendo subdividido por Nogueira e Riccomini (2006) em quatro formaçôes (da base para o topo): Mirassol d'Oeste, Guia, Serra do Quilombo e Nobres (Fig. 1).

A Formação Mirassol d'Oeste, de $20 \mathrm{~m}$ de espessura, consiste em dolomitos finos rosados e peloidais e estromatólitos, depositados em plataforma rasa e com base sobreposta diretamente ao diamictito da Formação Puga, por meio de um contato brusco e lateralmente irregular e ondulado, com deformaçôes plásticas atribuídas à sismicidade induzida por rebound pós-glacial e que representam o registro de uma rápida mudança das condiçóes glaciais para efeito estufa (Nogueira et al. 2003, Nogueira \& Riccomini 2006). Esta unidade é interpretada como uma capa dolomítica (Nogueira et al. 2003) depositada logo após a glaciação Puga, correlata à última do Criogeniano, tratando-se de um importante marco estratigráfico global por ser a base do período Ediacarano na região. A Formação Guia, com mais de $400 \mathrm{~m}$ de espessura, é constituída por calcários 
finos betuminosos, folhelhos betuminosos, pelitos vermelhos e cementstones com leques de cristais de calcita (pseudomorfos de aragonita) e laminação plana, interrompida localmente por brechas e estruturas de deformação. As camadas brechadas e deformadas podem ser relacionadas com o intumescimento do assoalho marinho causado pela concomitante cimentação e cristalização expansiva sinsedimentar (Kennedy 1996). A base da Formação Guia é considerada como a porção calcária da capa carbonática Puga (Nogueira et al. 2007).

A Formação Serra do Quilombo, com 100 m de espessura, é composta predominantemente por dolomitos finos maciços a laminados, dolomitos arenosos com estratificação cruzada hummocky, dolomitos arenosos/oolíticos com laminaçôes produzidas por ondas e brechas dolomíticas cimentadas e/ou com matriz. Esta unidade representa depósitos de plataforma moderadamente rasa à profunda influenciada por sismos e tempestades. Sua zona de contato com a Formaçáo Guia é marcada por um intenso fraturamento entre os dolomitos e calcários finos (Nogueira \& Riccomini 2006). A Formação Nobres, que tem até $200 \mathrm{~m}$ de espessura, consiste em dolomitos finos, dolomitos oolíticos subordinados e estromatólitos, além de dolomitos arenosos, brechas, ritmitos arenito/pelito e arenitos que são interpretados como depósitos de planície de maré/sabkha. Esses depósitos ocorrem por mais de $300 \mathrm{~km}$ de extensão na parte norte da Faixa Paraguai e estão organizados em ciclos métricos tabulares, lateralmente contínuos por centenas de metros, sendo que seu contato com a Formação Serra do Quilombo é irregular e marcado pela ocorrência de brechas e arenitos com clastos tabulares de micrito e gretas de contração (Nogueira \& Riccomini 2006).

O Grupo Araras é recoberto pela sucessão siliciclástica do Grupo Alto Paraguai, que consiste da base para o topo, de arenitos e pelitos (Formação Raizama), folhelhos e arenitos (Formação Sepotuba) e ritmitos vermelhos, arenitos finos e conglomerados (Formação Diamantino). Figueiredo et al. (2008) descreveram uma sucessão de diamictitos glaciais e siltitos, sobrepostos aos carbonatos pós-marinoanos do Grupo Araras na porção norte da Faixa Paraguai, denominando-a de Formação Serra Azul. Ainda segundo Figueiredo et al. (2008), esta unidade deveria ser incluída na base do Grupo Alto Paraguai e seria o primeiro registro glacial encontrado na América do Sul relacionado à glaciação gaskierana $(582 \mathrm{Ma})$. Apesar de até o momento não terem sido encontrados tufos ou corpos vulcânicos para definir uma idade precisa ao Grupo Araras, o método $\mathrm{Pb}-\mathrm{Pb}$ em carbonatos forneceu importantes resultados geocronológicos, tais como a idade isocrônica $\mathrm{Pb}-\mathrm{Pb}$ de $627 \pm 32 \mathrm{Ma}$ (Babinski et al. 2006), obtida para carbonatos da Formação Mirassol d'Oeste, base do Grupo Araras. Métodos de datação relativa, baseados principalmente no conteúdo microfossilífero (acritarcos e filamentos de cianobactérias), têm apontado idade ediacarana (620 a $580 \mathrm{Ma}$ ) para a base do Grupo Araras (Hidalgo et al. 2008). A geocronologia U-Pb de zircão detrítico do topo da Formação Diamantino tem apontado a idade máxima de $541 \pm 7$ Ma para o final da sedimentação da Faixa Paraguai (Bandeira et al. 2011).

\section{FORMAÇÃO SERRA DO QUILOMBO}

\section{Aspectos gerais}

A sucessão estudada possui aproximadamente $140 \mathrm{~m}$ de espessura e inclui a Formação Serra do Quilombo e seus contatos com unidades adjacentes, Formação Guia na base e a Formação Nobres, no topo (Figs. 2 e 3). A zona de contato entre as formaçóes Guia e Serra do Quilombo (Fig. 4) é marcada pelo aparecimento de uma grande quantidade de cimento dolomítico associada a um intenso fraturamento dos carbonatos, representados por espessos pacotes (de até $5 \mathrm{~m}$ ) de brechas dolomíticas cimentadas. Estes se alojam no acamamento e truncam tanto os dolomitos finos da Formação Serra do Quilombo, quanto os calcários finos betuminosos da Formação Guia (Figs. 2 a 4). Essas brechas cimentadas foram previamente interpretadas como sindeposicionais (Nogueira 2003, Nogueira \& Riccomini 2006, Nogueira et al. 2007). Neste trabalho, admitiu-se uma origem tectônica/hidrotermal, portanto, tais brechas não foram incluídas na interpretação de fácies. No entanto, dentre todas as unidades ocorrentes na Faixa Paraguai Norte, as brechas cimentadas são encontradas quase que exclusivamente na Formação Serra do Quilombo, sendo uma de suas características inerentes. A explicação para essa ocorrência particular pode estar relacionada à natureza reológica dos dolomitos finos, sendo um aspecto ainda a ser melhor entendido. O contato com a Formação Nobres é gradacional, caracterizado pelo aparecimento dos primeiros níveis silicificados e por um pacote de brecha dolomítica maciça com matriz (Fig. 4), de até $4 \mathrm{~m}$ de espessura. O sílex, de coloração escura ou esbranquiçada, preenche cavidades, limites de camadas e substitui parcialmente os carbonatos, formando nódulos métricos de sílica. A matriz da brecha consiste em dolomito cristalino fino, que envolve clastos tabulares a subarredondados de dolomito cristalino oolítico. Embora a passagem entre a brecha dolomítica com matriz (BDm) e os dolomitos seja brusca, não há mudanças de litotipo, o qual ainda permanece como dolomito, e a ciclicidade, a qual inclui depósitos de face litorânea passando para ciclos de perimaré da Formaçáo Nobres, indica uma transição de fácies sem interrupção na sedimentação (Rudnitzki 2011). 

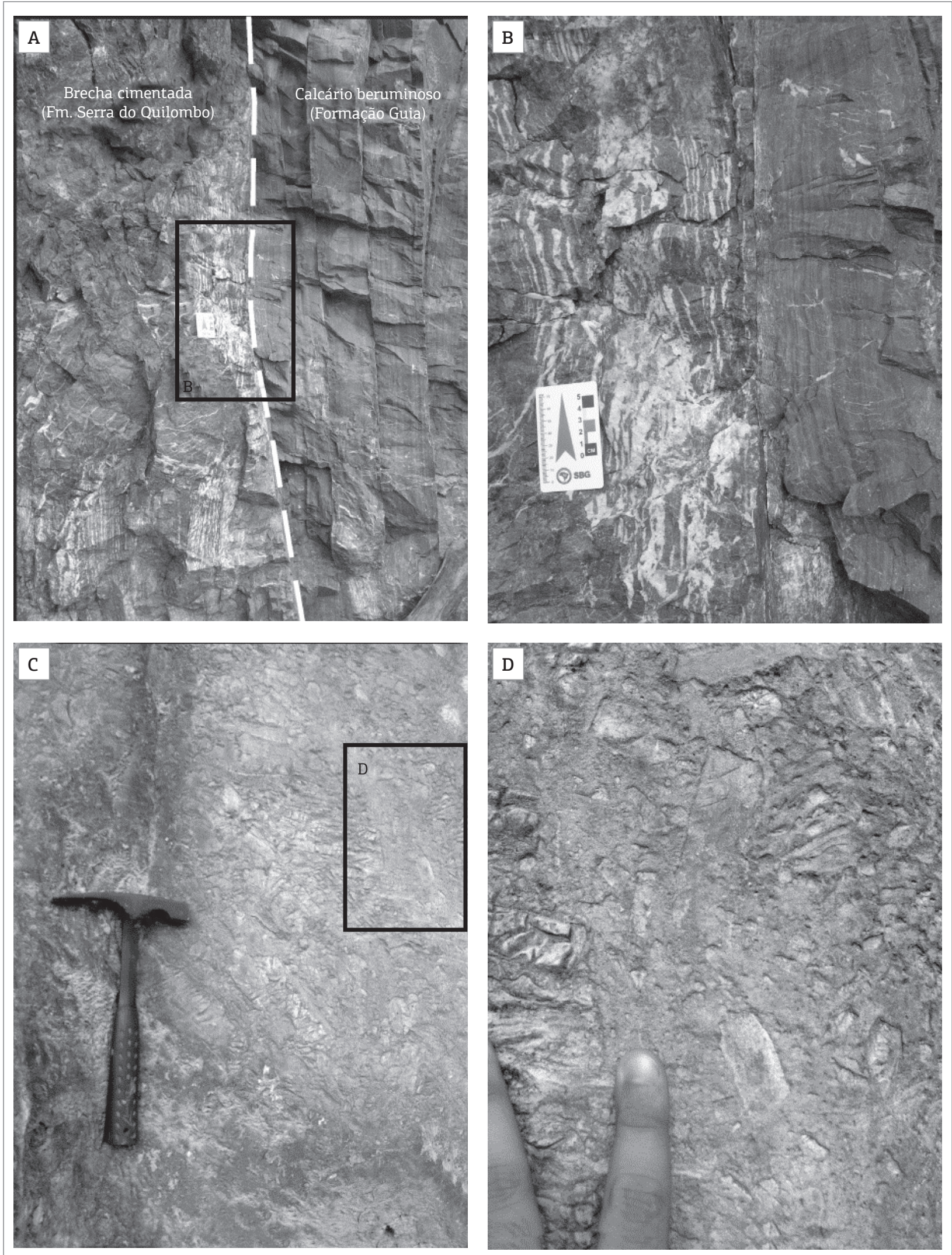

Figura 4. Contatos da Formação Serra do Quilombo. (A e B) zona de contato inferior com a Formação Guia; (C e D) brecha dolomítica com matriz da zona de contato superior com a Formação Nobres. 
As rochas carbonáticas pertencentes à Formação Serra do Quilombo formam camadas tabulares de cor cinza claro e escura (quando contêm matéria orgânica); amareladas e esbranquiçadas, quando intemperizadas; e são representadas por brechas dolomíticas com cimento e/ou com matriz intercaladas com dolomitos finos (dolomudstones), arenosos e oolíticos, podendo conter até $35 \%$ de grãos terrígenos (quartzo, feldspatos e micas). Os processos secundários de silicificação e neomorfismo/dolomitização são comuns e modificaram as texturas micrítica e espática originais de algumas fácies. Aqueles de compactação e dissolução por pressão são indicados por grãos deformados (ooides e terrígenos) e planos de estilólitos. Outras feiçôes secundárias observadas são os bolsôes e vugs preenchidos por dolomita espática, minerais de óxidos e hidróxidos de ferro disseminados e que formam textura dendrítica, ocorrência localizada de sulfetos, além de falhas sinsedimentares, fraturas e vênulas. As estruturas sedimentares dos carbonatos muitas vezes são de difícil visualização, principalmente devido aos processos de silicificação, neomorfismo e alterações geradas por eventos pedogenéticos recentes.
Foram identificadas, na Formação Serra do Quilombo, cinco fácies deposicionais, a saber: dolomito fino laminado rico em matéria orgânica $(\mathrm{Dl})$, dolomito fino maciço a laminado (DmL), dolomito arenoso com estratificação cruzada hummocky/swaley associada com estratificação plano-paralela (DAh), dolomito arenoso/oolítico com laminaçóes produzidas por ondas (DAl) e $\mathrm{BDm}$. As fácies sedimentares foram agrupadas em duas associaçôes de fácies $(\mathrm{AF})$, as quais indicam ambientes de plataforma carbonática profunda à moderadamente rasa $(\mathrm{AF} 1: \mathrm{Dl}$ e $\mathrm{DmL})$ e face litorânea influenciada por tempestades (AF2: DAh, DAl e BDm), como observado na Tab. 1 e Fig. 2, confirmando as interpretaçôes prévias de Nogueira e Ricommini (2006).

\section{Associação de fácies \\ Plataforma profunda à moderadamente rasa}

Essa AF é formada por camadas de DmL e Dl, que alcançam intervalos de até $45 \mathrm{~m}$ de espessura e constituem a porção inferior da Formação Serra do Quilombo (Fig. 2). As fácies DmL e Dl (Fig. 5 e Tab. 1) formam camadas tabulares contínuas e apresentam textura dominantemente micrítica (dolomudstone, $<20 \mu \mathrm{m}$, segundo

Tabela 1. Sumário das fácies e associações de fácies da Formação Serra do Quilombo

\begin{tabular}{|c|c|c|c|}
\hline $\begin{array}{l}\text { Associação de } \\
\text { fácies }\end{array}$ & Fácies & Estruturas & Processo deposicional/diagenético \\
\hline \multirow{2}{*}{$\begin{array}{l}\text { AF1 } \\
\text { Plataforma } \\
\text { profunda à } \\
\text { moderadamente } \\
\text { rasa }\end{array}$} & $\begin{array}{l}\text { Dolomito fino maciço a laminado } \\
\text { (Dml): Dolomudstone ou dolomito } \\
\text { cristalino muito fino (<16 } \mu \mathrm{m}) \text {. } \\
\text { Grãos de terrígenos (quartzo, } \\
\text { feldspato e mica). }\end{array}$ & $\begin{array}{l}\text { Laminação plano-paralela e } \\
\text { acamamento maciço. }\end{array}$ & $\begin{array}{l}\text { Precipitação química de lama } \\
\text { carbonática com alta e/ou moderada } \\
\text { segregação das partículas, em } \\
\text { ambiente de baixa energia. } \\
\text { Neomorfismo. }\end{array}$ \\
\hline & $\begin{array}{l}\text { Dolomito fino laminado } \\
\text { com matéria orgânica (Dl): } \\
\text { Dolomudstone ou dolomito } \\
\text { cristalino muito fino (<16 } \mu \mathrm{m}) \text {. } \\
\text { Grãos de terrígenos (quartzo, } \\
\text { feldspato e mica). }\end{array}$ & $\begin{array}{l}\text { Laminação plano-paralela. Planos } \\
\text { de dissolução com matéria orgânica. }\end{array}$ & $\begin{array}{l}\text { Precipitação química de lama } \\
\text { carbonática associada à decantação de } \\
\text { matéria orgânica em ambiente anóxico } \\
\text { de baixa energia. }\end{array}$ \\
\hline \multirow{3}{*}{$\begin{array}{l}\text { AF2 } \\
\text { Face litorânea } \\
\text { influenciada por } \\
\text { tempestades }\end{array}$} & $\begin{array}{l}\text { Dolomito arenoso com } \\
\text { estratificação cruzada hummocky/ } \\
\text { swaley (DAh): Dolomito cristalino } \\
\text { fino (<62 } \mu \text { m) com até } 35 \% \text { de } \\
\text { grãos de terrígenos (quartzo, } \\
\text { feldspato e mica) do tamanho silte } \\
\text { à areia muito fina. }\end{array}$ & $\begin{array}{c}\text { Estratificação cruzada hummocky/ } \\
\text { swaley, associada com } \\
\text { estratificação plano-paralela } \\
\text { à cruzada de baixo ângulo. } \\
\text { Laminação plano-paralela. Falhas } \\
\text { e microfalhas sinsedimentares } \\
\text { associadas a pacotes de brecha } \\
\text { dolomítica com matriz (fácies } \\
\text { BDm). Acamamento convoluto. }\end{array}$ & $\begin{array}{l}\text { Deposição por fluxo combinado } \\
\text { dominantemente oscilatório de ondas } \\
\text { de tempestades. Deposição por fluxo } \\
\text { em lençol (flat bed). Migração de } \\
\text { marcas onduladas. Ajustamentos } \\
\text { plásticos e rúpteis relacionados } \\
\text { ao agitamento do substrato por } \\
\text { impacto de ondas de tempestades. } \\
\text { Neomorfismo. }\end{array}$ \\
\hline & $\begin{array}{l}\text { Dolomito arenoso/oolítico com } \\
\text { laminações produzidas por onda } \\
\text { (DAL): Dolomito cristalino fino a } \\
\text { médio ( } 10 \text { a } 200 \mu \mathrm{m} \text { ) com grãos } \\
\text { de terrígenos (quartzo, feldspatos } \\
\text { e micas). Dolograinstone oolítico, } \\
\text { por vezes silicificado. }\end{array}$ & $\begin{array}{c}\text { Laminação cruzada truncada } \\
\text { por ondas, com arranjo em } \\
\text { chevron, laminações cruzadas } \\
\text { em direções opostas, feixes de } \\
\text { laminação cruzada agradacionais, } \\
\text { lâminas com padrão pinch e swell, } \\
\text { laminação quasi-planar. }\end{array}$ & $\begin{array}{l}\text { Migração de marcas onduladas por } \\
\text { fluxo combinado resultante do declínio } \\
\text { de tempestade. Neomorfismo. }\end{array}$ \\
\hline & $\begin{array}{l}\text { Brecha dolomítica com matriz } \\
\text { (BDm): Clastos da fácies DAh e } \\
\text { DAl. Matriz de dolomito cristalino } \\
\text { fino a médio (10 a } 200 \mu \mathrm{m}), \\
\text { arenoso e oolítico. }\end{array}$ & $\begin{array}{c}\text { Clastos de dolomito arenoso e } \\
\text { oolítico imbricados em arcabouço } \\
\text { fechado e/ou disseminados em } \\
\text { arcabouço aberto. Matriz maciça, } \\
\text { localmente com estruturas de } \\
\text { liquefação. }\end{array}$ & $\begin{array}{c}\text { Fraturamento e desarticulação das } \\
\text { camadas de carbonato parcialmente } \\
\text { litificado por impacto das ondas de } \\
\text { tempestades. Liquefação e fluidização. } \\
\text { Neomorfismo. }\end{array}$ \\
\hline
\end{tabular}



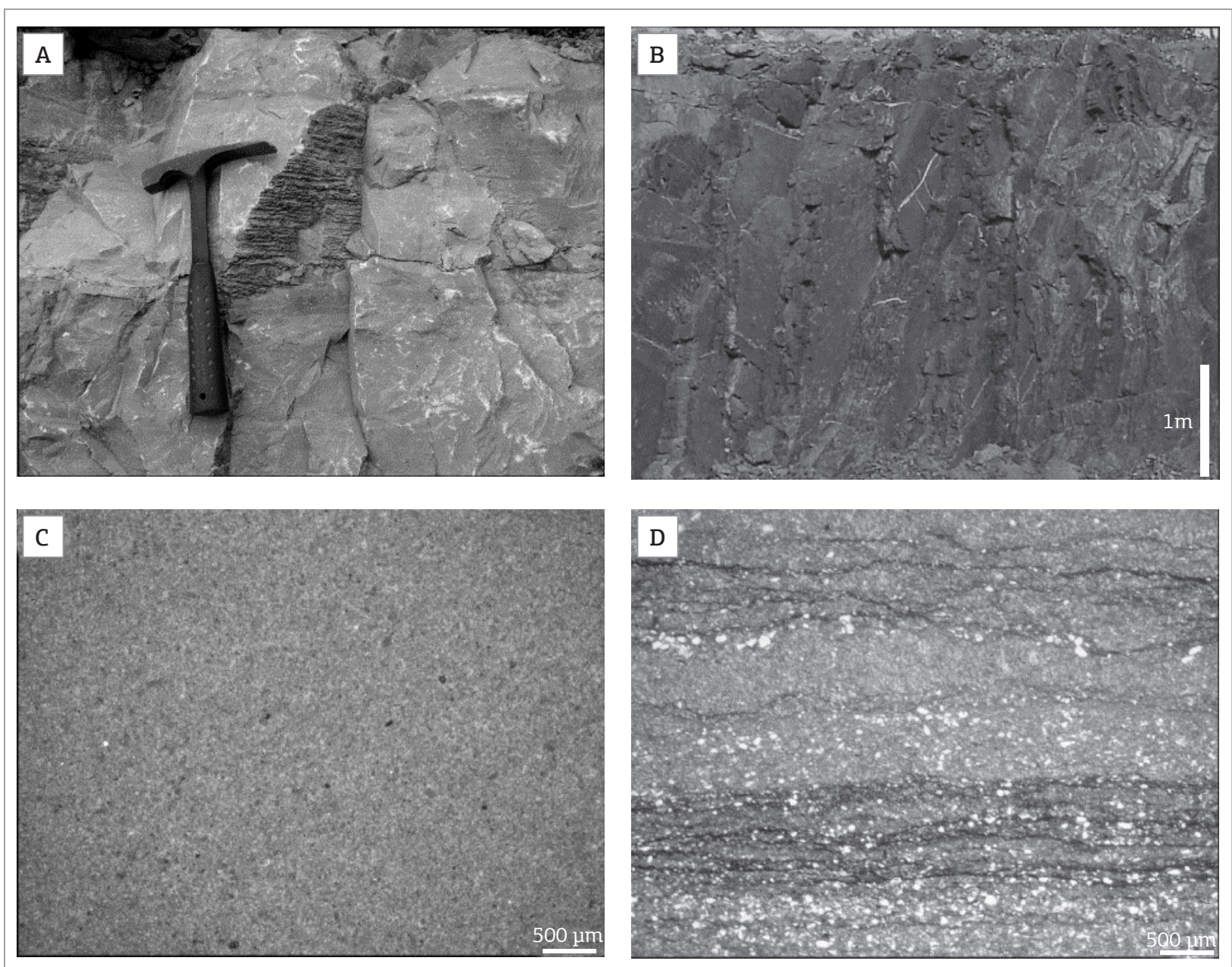

Figura 5. Dolomito fino maciço e laminado (Dml/Dl). (A) detalhe para laminação plano-paralela; (B) dolomito em camadas verticais impregnado com matéria orgânica, da zona de contato inferior com a Formação Guia; (C) fotomicrografia de dolomito fino maciço (Px-polarizador cruzado; (D) dolomito fino com grãos terrígenos e partições de dissolução (dissolution seams), P//-polarizador paralelo.

Dunham 1962). Localmente, ocorrem dolomitos cristalinos $(<62 \mu \mathrm{m})$ com textura não planar (mosaico xenotópico). Grãos terrígenos (quartzo, feldspato e mica) de tamanho areia fina a muito fina, minerais opacos (pirita/ magnetita?), matéria orgânica e resquícios de calcita são comuns, principalmente na fácies $\mathrm{Dl}$ da zona de contato com a Formação Guia.

Os DmL/Dl representam a deposição de baixa energia a partir de suspensão, abaixo da base de onda da tempestade em plataforma carbonática. A precipitação química de lama carbonática, com alta e/ou moderada segregação das partículas, favoreceu a formação, respectivamente, dos DmL. A posterior obliteração da laminação por processos diagenéticos também contribuiu com a ocorrência de dolomitos maciços. A abundância de matéria orgânica (Dl), preservada principalmente em planos de dissolução (dissolution seams), sugere um ambiente anóxico para o início da sedimentação da Formação Serra do Quilombo, o que provavelmente possui certa contiguidade com a fase final de deposição da plataforma profunda da Formação Guia.

\section{Face litorânea influenciada por tempestades}

A AF2 é formada por depósitos de face litorânea (shoreface) que incluem tempestitos amalgamados, constituídos por camadas de DAh e pacotes de BDm, sobrepostos por DAl, conforme observado nas Figs. 2 e 3 e na Tab. 1 . Essa associação de fácies alcança aproximadamente $40 \mathrm{~m}$ de espessura e representa a porção superior da Formação Serra do Quilombo, até o presente, de ocorrência restrita à seção-tipo da unidade.

Os dolomitos arenosos da fácies DAh formam bancos amalgamados em sucessóes de até $10 \mathrm{~m}$ de espessura (Figs. 2 e 3B) e mostram acamamento de megamarcas onduladas, referidos como estratificação cruzada hummocky $(\mathrm{ECH})$, 
os quais alcançam comprimentos de até $3 \mathrm{~m}$ e amplitude de $0,5 \mathrm{~m}$ (Fig. 3C). Tais estratos apresentam estratificação plano-paralela à cruzada de baixo ângulo (entre 10 e $15^{\circ}$ ), associadas com a estratificação cruzada hummocky/swaley (Dumas \& Arnott 2006), como visto nas Figs. 6A a C, além de acamamento convoluto e falhas/microfalhas sinsedimentares. As camadas com ECH apresentam espessamentos e adelgaçamentos sistemáticos, os quais tornam sua espessura variável $(0,1$ a $2 \mathrm{~m})$, onde cada camada está em contato erosional com a inferior. Essas truncam pacotes ondulados e lateralmente contínuos, com estratificação interna plano-paralela ou quasi-planar (ondulada e com estratos de baixo ângulo; $c f$. Dumas \& Arnott 2006). A presença de falhas e microfalhas sinsedimentares, bem como de acamamento convoluto, está associada aos pacotes de brecha dolomítica com matriz da fácies BDm.

Os dolomitos arenosos/oolíticos da fácies DAl apresentam laminaçóes cruzadas, plano-paralelas, marcas onduladas e bases erosivas de sets (Fig. 6D). A laminação cruzada pode apresentar-se truncada por ondas, com arranjo em chevron, em direçōes opostas, formando feixes agradacionais, com padrōes pinch e swell, e como laminação quasi-planar. As marcas onduladas simétricas ou assimétricas mostram internamente laminaçóes bidirecionais com bases erosivas indicativas da influência de fluxo oscilatório (segundo os critério de De Raff et al. 1977). Esse conjunto de estruturas produzidas por ondas e/ou corrente de retorno sugere a deposição em face litorânea superior (Tucker \& Wright 1990).

Petrograficamente, observa-se dolomita muito fina à média (10 a $200 \mu \mathrm{m}$ ), algumas vezes formando agregados, porçôes da rocha com até $35 \%$ de grãos terrígenos (quartzo, feldspato e mica), minerais opacos e ooides (Fig. 7). Os grãos de quartzo (mono e policristalino) e feldspato (principalmente plagioclásio) são, em geral, do tamanho silte a areia fina (subangulosos a subarredondados), raramente areia média (bem arredondados). As micas formam palhetas incolores a luz natural e os minerais opacos, por vezes, são
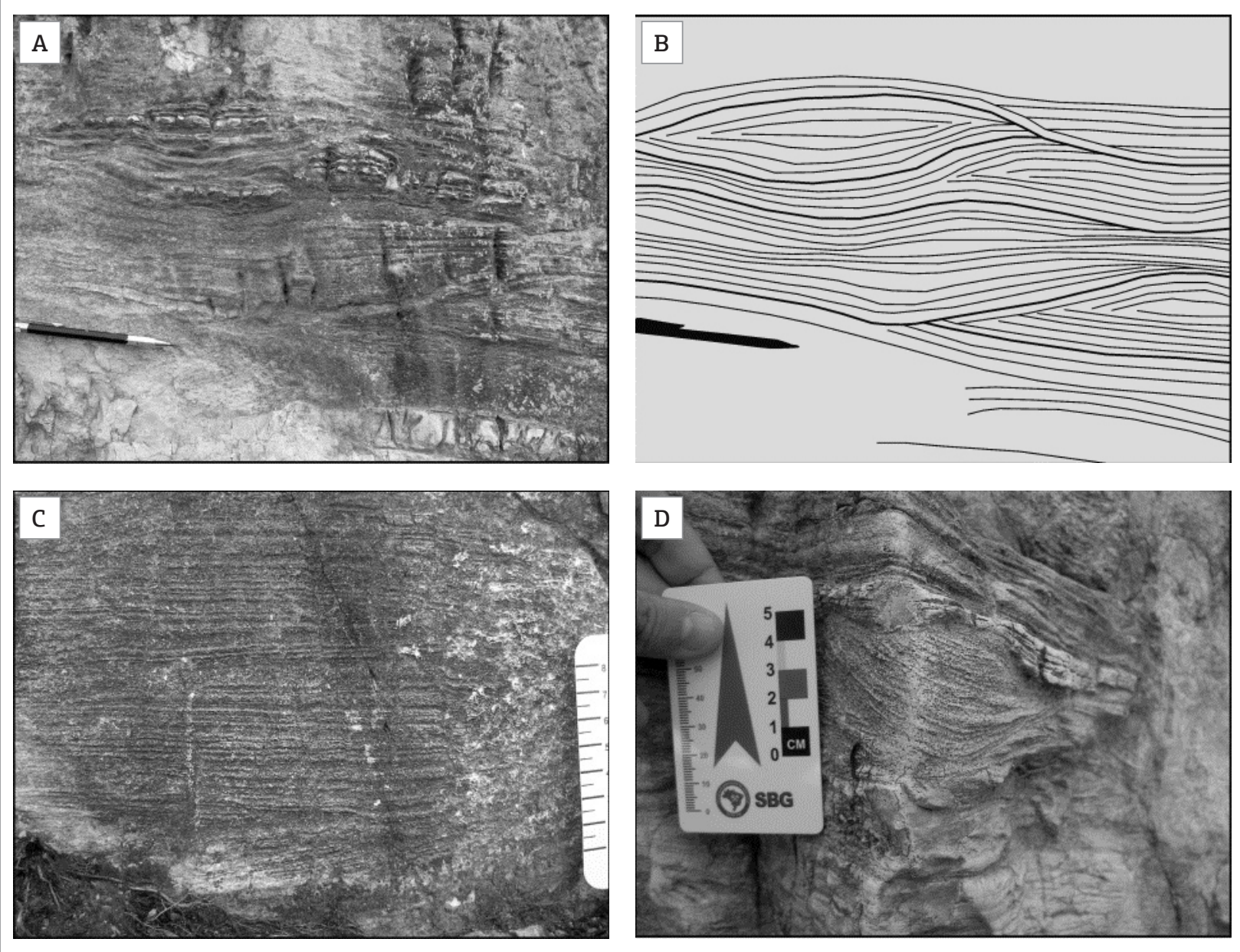

Figura 6. Estruturas sinsedimentares da associação de fácies 2. (A) estratificação cruzada hummocky/swaley; (B) desenho esquemático de A destacando os truncamentos de baixo ângulo e a geometria ocelar da estrutura; (C) laminação plana com truncamentos de baixo ângulo (escala = $10 \mathrm{~cm}$ ); (D) base erosiva produzida por ondas. 
cúbicos e hexagonais. Os ooides, geralmente silicificados ou dolomitizados, variam em diâmetro de 2 a 0,2 m, com média de 0,6 mm, e são abundantes em direção ao topo da unidade, no qual formam dolomitos essencialmente oolíticos (oólitos), típicos da zona de contato superior (Fig. 7D).

As $\mathrm{BDm}$ estruturam camadas lenticulares descontínuas de até $5 \mathrm{~m}$ de espessura, que se alojam tanto nos dolomitos arenosos da fácies DAh, quanto nos arenosos/oolíticos da fácies DAl, estes na zona de transição para a Formação Nobres. O contato entre brechas e dolomitos é marcado, em geral, por fraturas e falhas que se rompem e desagregam as camadas de dolomitos, formando os pacotes de brecha (Figs. 8A e B). As brechas da fácies $\mathrm{BDm}$ são constituídas por clastos de dolomito arenoso e oolítico (Fig. 8C), com tamanhos que variam de seixo até matacão, e matriz de dolomito cristalino fino a médio (10 a $200 \mu \mathrm{m})$, por vezes com grãos terrígenos e ooides. A proporção textural entre clastos e matriz é variável, de tal forma que as brechas podem ser sustentadas por clastos ou pela matriz, seja com clastos imbricados em arcabouço fechado e/ou disseminados em um arcabouço aberto (com alta ou baixa concentração).

De acordo com Nogueira (2003), a estrutura de dissolução por pressão em clastos (contato côncavo-convexo) ocorre localmente nas porçôes de arcabouço fechado, bem como matriz maciça com estruturas de liquefação. Ainda, nas proximidades de falhas normais sinsedimentares, os clastos encontram-se verticalizados e com eixos maiores dispostos paralelamente a estas, o que não ocorre nas porçóes mais afastadas, nas quais os mesmos chegam a apresentar estruturas in fitting.

A presença de estratificação cruzada hummocky/swaley é característica da atuação de tempestades em depósitos de face litorânea inferior (Galloway \& Hobday 1996), e sua ocorrência tem sido atribuída ao desempenho das ondas de
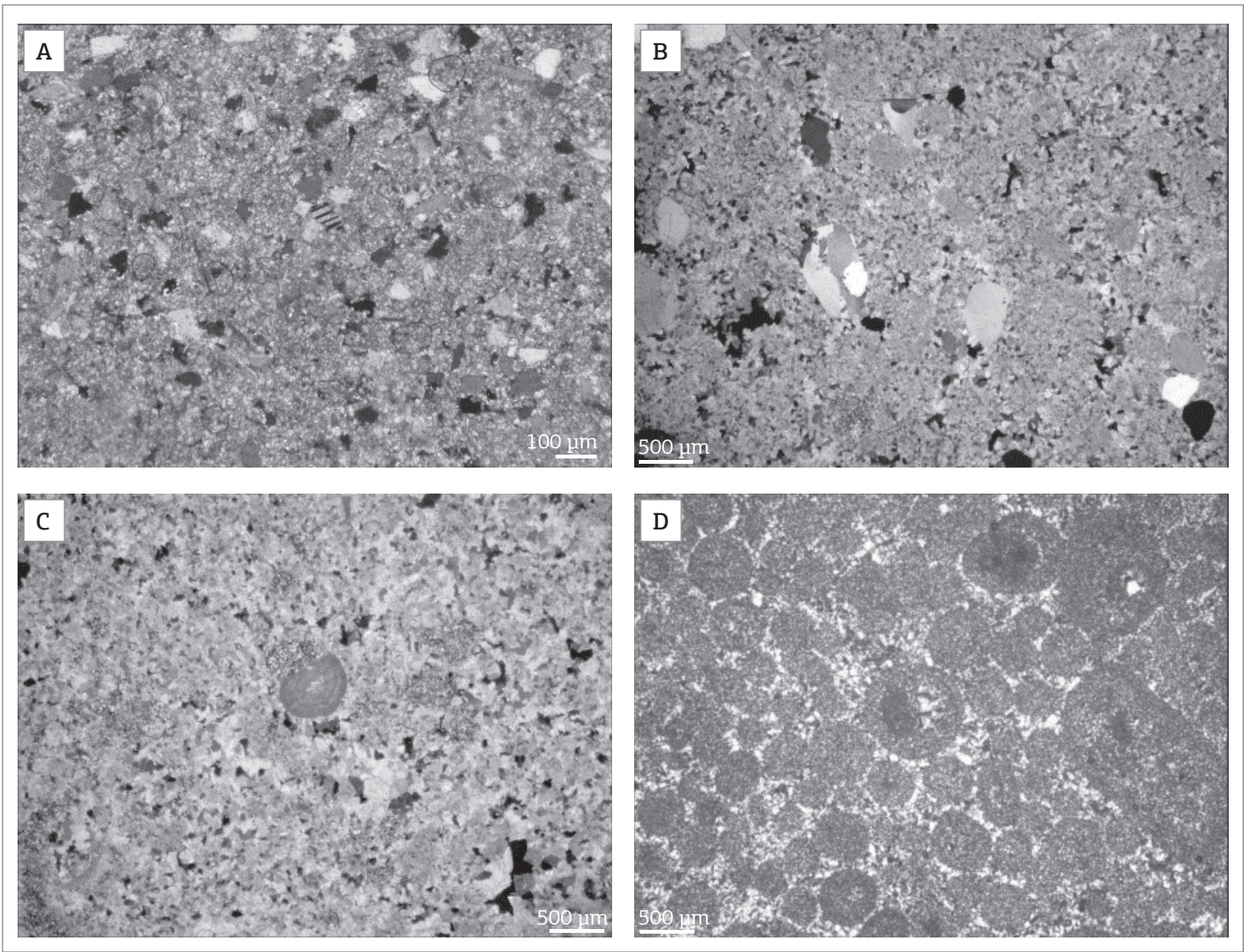

Figura 7. Aspectos petrográficos dos dolomitos arenosos/oolíticos da associação de fácies 2. (A) dolomito arenoso (DAh) com até 35\% de terrígenos (grãos de quartzo, feldspato e micas); (B) dolomito arenoso/oolítico (DAL) com ooides dolomitizados e silicificados e grãos de quartzo mono e policristalinos; (C) dolomito oolítico (DAL) com agregados de dolomita espática e ooides dolomitizados e silicificados; (D) oólito silicificado (DAL) da zona de contato com a Formação Nobres. 
tempestades responsáveis pelo desenvolvimento de intensos fluxos combinados e/ou oscilatórios capazes de retrabalhar sedimentos depositados em profundidades de até $200 \mathrm{~m}$, já na plataforma externa (offshore) (Harms et al. 1982, Cheel \& Leckie 1993). Segundo Dumas e Arnott (2006), a ECH se faz de maneira ideal acima da base da onda de tempestade, no momento em que as taxas de agradação são elevadas o suficiente para preservar hummocks e a velocidade das correntes unidirecionais é suficientemente baixa para gerar estratificação cruzada isotrópica e de baixo ângulo.

A estratificação cruzada swaley é também produzida entre a base de onda desenvolvida em tempo bom e aquela sob tempestade, mas em águas mais rasas, onde as taxas de agradação são baixas o suficiente para causar a preservação preferencial de swales. Os corpos carbonáticos com estratificação cruzada hummocky/swaley exibem granulação de areia fina à média e formam camadas espessas e amalgamadas relacionadas a depósitos proximais representativos de sedimentação em plataforma rasa (Duke \& Prave 1992, McCrory \& Walker 1986, Cheel \& Leckie 1993). As camadas planas (flat beds, segundo Duke et al. 1991) seriam geradas por fluxos oscilatórios de alta velocidade, em regime de fluxo superior e/ou combinados com predominância da componente unidirecional.

A gradual transição entre as camadas de dolomitos arenosos e oolíticos para os pacotes de brecha contendo fragmentos da própria unidade (clastos de dolomitos arenosos e/ou oolíticos) demonstra claramente que a formação da brecha ocorreu como resultado de um processo de fragmentação in situ dos sedimentos parcialmente litificados. Nesse sentido, tal construção pode ser o resultado da liquefação parcial de um carbonato argiloso sob efeito da carga induzida por ondas cíclicas durante tempestades tropicais, como descrito por Bouchette et al. (2001). As orbitais de ondas exercem uma pressão no fundo marinho, a qual induz o deslocamento dos sedimentos, cuja magnitude varia
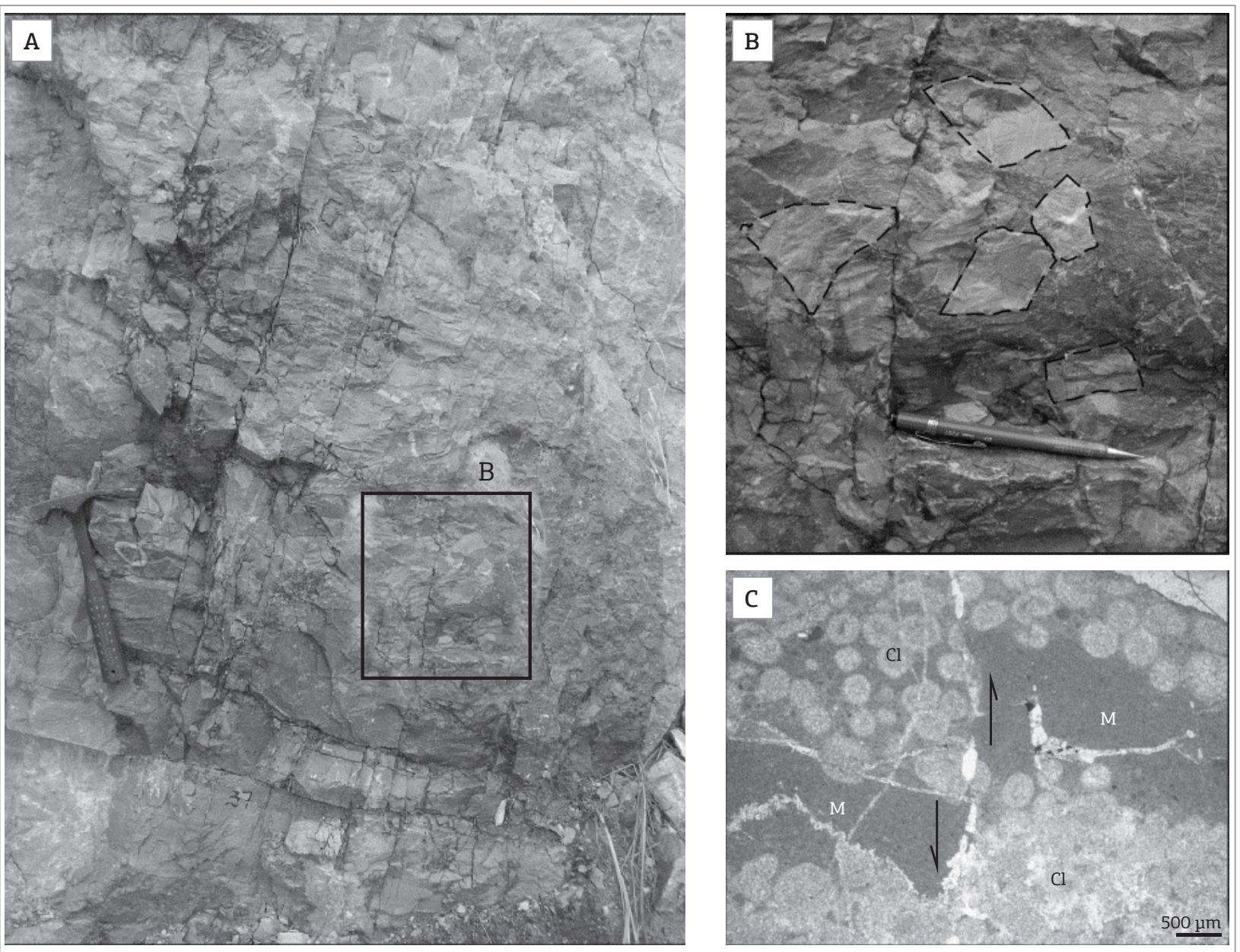

Figura 8. Brechas dolomíticas com matriz da Formação Serra do Quilombo. (A) brecha dolomítica com matriz maciça associada com fraturas e falhas sinsedimentares; (B) detalhe de A, mostrando clastos, sem nenhum tipo de gradação, imersos em matriz maciça; (C) fotomicrografia mostrando os clastos (CL) de dolomito oolítico e matriz (M) dolomítica fina (P//). Notar deslocamento da matriz e clastos por microfalha em C. 
com a altura e o comprimento das ondas. No fundo marinho, estas orbitais induzem estresse cisalhante e paulatinamente deformam o arcabouço de partículas da lama carbonática. Essa deformação leva ao progressivo aumento na pressão do poro e liquefação da lama. Desta forma, o fundo marinho torna-se uma mistura de clastos flutuando em lama liquefeita, que se comporta como líquido de alta viscosidade. Um decréscimo na energia da onda resulta na deposição da mistura liquefeita e na formação de brechas com matriz. A relação das brechas com as estruturas indicativas da atuação de tempestades sugere que o processo de brechação ocorreu, provavelmente, sob ação da carga de orbitais das ondas cíclicas.

\section{Modelo deposicional}

A Formação Serra do Quilombo representa depósitos carbonáticos marinhos de plataforma profunda à moderadamente rasa (rampas externa e média) e de face litorânea influenciada por tempestades (rampa interna). Esses depósitos representam a plataforma carbonática Araras no sudeste do Cráton Amazônico formada durante o Ediacarano. A deposição da parte inferior da Formação Serra do Quilombo (AFl) é marcada pela ocorrência de dolomitos finos maciços e laminados de plataforma carbonática marinha, que sobrepóem calcários finos betuminosos de plataforma profunda anóxica da Formação Guia e representam deposição de baixa energia abaixo da base de onda de tempestade. Esses dolomitos foram sendo gradualmente sobrepostos por dolomitos arenosos com estratificação cruzada hummocky/swaley (tempestitos amalgamados) e dolomitos arenosos/oolíticos com laminaçóes produzidas por ondas, da porção superior da unidade (AF2), caracterizando uma sucessão de raseamento ascendente (shallowing upward). As brechas dolomíticas com matriz (sinsedimentares), intercaladas com os dolomitos da AF2, são consideradas como produtos de retrabalhamento do assoalho marinho por eventos episódicos, relacionados à ação de ondas de tempestades em face litorânea inferior (AF2). As barras ou cordóes litorâneos arenosos/ oolíticos podem ter sido responsáveis localmente pelo

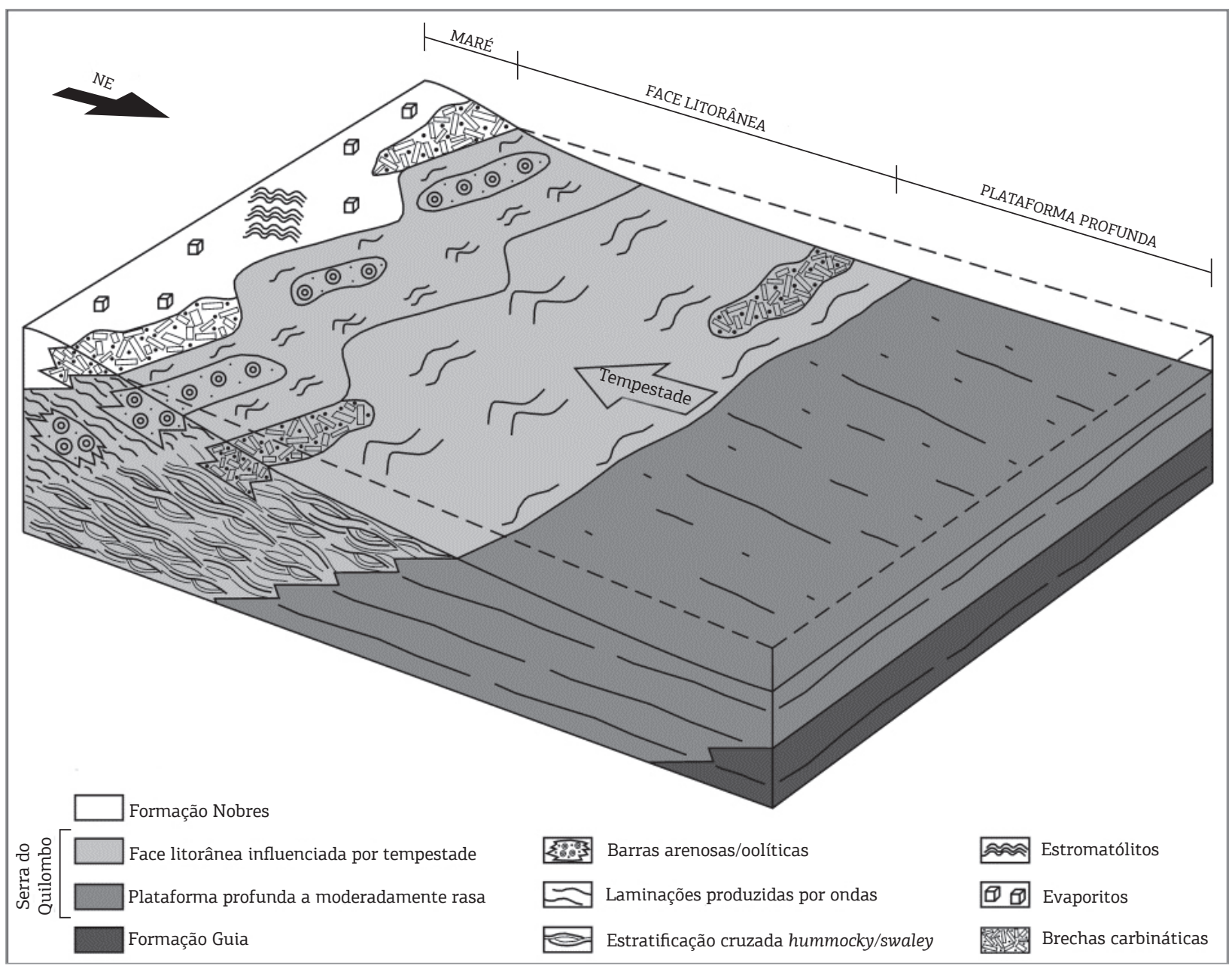

Figura 9. Sistema deposicional da Formação Serra do Quilombo. 
confinamento das porçôes de rampa interna, favorecendo o desenvolvimento das fácies evaporíticas, de microbialitos e brechas da Formação Nobres.

$\mathrm{O}$ crescente influxo de grãos terrígenos em direção ao topo da sucessão estudada, marcado pela ocorrência de barras arenosas/oolíticas retrabalhadas por ondas e tempestade, seguida pela implantação das planícies de maré/sabkha da Formação Nobres, caracteriza o início da transição de depósitos essencialmente carbonáticos para mistos (carbonáticos/siliciclásticos). Essa constatação, aliada ao fato de que a Formação Serra do Quilombo sobrepóe depósitos de plataforma profunda anóxica, da Formação Guia, indica uma progradaçáo desses depósitos, possivelmente em um trato de sistema de mar alto.

A sucessão de fácies carbonáticas estudada apresenta uma série de características particulares importantes para a definição de seu sistema deposicional, dentre essas estấo: ausência de depósitos produzidos por fluxos de detritos, turbiditos e brechas associadas; fácies com intraclastos provenientes dos depósitos da própria plataforma/rampa e caráter tabular das camadas e sua ampla continuidade lateral. Rampas carbonáticas são plataformas suavemente inclinadas (geralmente $<1^{\circ}$ ), nas quais fácies de águas rasas dominadas por ondas da zona costeira passam gradualmente para depósitos de águas profundas de baixa energia (Ahr 1973 in Read 1982). Rampas homoclinais podem apresentar complexos de barras arenosas/oolíticas, que gradam sem quebra no talude para calcários de rampa profunda e, finalmente, para fácies bacinais pelágicas/hemipelágicas. Além disso, não apresentam significantes depósitos de slump e fluxo gravitacional nas fácies de água profunda (Read 1982), que podem ocorrer em baixas declividades $\left(<0,25^{\circ}\right)$, principalmente quando acionado por gatilho sísmico (Ringrose 1989).

Baseando-se nessas informaçôes e de acordo com a classificação das plataformas carbonáticas de Read (1982, 1985), atribuiu-se, para os depósitos carbonáticos da Formação Serra do Quilombo, um modelo deposicional em rampa carbonática homoclinal (Fig. 9), confirmando o modelo de plataforma aproximadamente horizontal extensa por centenas de quilômetros, já anteriormente admitido para a deposição dos carbonatos do Grupo Araras, por diversos autores (Almeida 1964, Boggiani 1997, Nogueira 2003, entre outros).

\section{CONCLUSÕES}

O estudo faciológico da Formação Serra do Quilombo nas regióes de Cáceres e Nobres permitiu o reconhecimento de cinco fácies deposicionais que correspondem a Dl, DmL, DAh, DAl e BDm. As fácies sedimentares foram agrupadas em duas $\mathrm{AF}$, as quais indicam ambientes de plataforma carbonática profunda à moderadamente rasa (AF1: Dl e DmL) e face litorânea influenciada por tempestades (AF2: DAh, DAl e BDm), compondo uma sucessão de raseamento ascendente (shallowing upward), progradante, relacionada a um trato de sistema de mar alto, em um contexto de rampa carbonática homoclinal.

Depósitos de plataforma profunda à moderadamente rasa (AFl) da Formação Serra do Quilombo, anteriormente considerados como pertencentes à Formação Nobres (Alvarenga et al. 2009), ocorrem em vários afloramentos na regiāo de Nobres, no Mato Grosso, indicando a extensão e continuidade da unidade por toda Faixa Paraguai Norte.

\section{AGRADECIMENTOS}

À Agência Nacional do Petróleo (ANP), que apoiou este trabalho e concedeu bolsa de estudo no nível de mestrado ao primeiro autor por meio do Programa de Recursos Humanos para o Setor Petróleo, Gás Natural e Biocombustíveis (PRH), parte de um convênio entre a Universidade Federal do Pará - UFPA, a ANP e o PRH-06. Ao Instituto Nacional de Ciência e Tecnologia de Geociências da Amazônia (GEOCIAM), coordenado por Roberto Dall'Agnol, ao Programa Procad/CAPES (Projeto 096/2007), coordenado por Moacir Macambira, e ao Projeto MCT/CNPq 014/2010: “Tectônica e Estratigrafia do Sudeste da Faixa Paraguai (MT) e suas implicaçôes com o Sistema Petrolífero Araras do Neoproterozóico", coordenado por Afonso Nogueira, pelo financiamento dos trabalhos de campo.

\section{REFERÊNCIAS}

Adams A.E., Mackenzie W.S., Guilford C. 1984. Atlas of sedimentary rocks under the microscope. Longman, Harlow, 140 p.

Allen P.A. \& Hoffman P.F. 2005. Extreme winds and waves in the aftermath of a Neoproterozoic glaciation. Nature, 433:123-127
Alkmin F.F., Marshak S., Fonseca M.A. 2001. Assembling West Gondwana in the Neoproterozoic: Clues from the São Francisco Craton region, Brazil. Geology, 29:319-322.

Almeida F.F.M. 1964. Geologia do Centro-Oeste Matogrossense. Rio de Janeiro, DNPM, Boletim 215, p. 1-53. 
Almeida F.F.M. 1968. Evolução tectônica do centro-oeste brasileiro no Proterozóico Superior. Anais da Academia Brasileira de Ciências, 40:285-293.

Almeida F.F.M. 1984. Província Tocantins, setor sudoeste. In Almeida F.F.M. \& Hasui Y. (coords). O Pré-Cambriano do Brasil. São Paulo, Blücher Ltda, p. 265-281.

Alvarenga C.J.S., Santos R.V., Dantas E.L. 2004. C-O-Sr isotopic stratigraphy of cap carbonates overlying Marinoan-age glacial diamictites in the Paraguay Belt, Brazil. Precambrian Research, 131:1-21.

Alvarenga C.J.S., Boggiani P.C., Babinski M., Dardenne M.A., Figueiredo M.F., Santos R.V., Dantas E.L. 2009. The Amazonian Palaeocontinent. In: Gaucher C., Sial A.N., Halverson G.P., Frimmel H.E. (eds). Neoproterozoic-Cambrian Tectonics, Global Change and Evolution: a focus on southwestern Gondwana. Developments in Precambrian Geology, 16, Elsevier, p. 15-28.

Babinski M., Trindade R.I.F., Alvarenga J.C., Boggiani P.C., Liu D., Santos R.V. 2006. Geochronological constraints on the Neoproterozoic glaciations in Brazil. In: Snowball Earth 2006, Ascona, Proceedings, v. 1. p. 19-20.

Bandeira J., McGee B., Nogueira A.C.R., Collins A.S., Trindade R. 2011. Sedimentological and provenance response to Cambrian closure of the Clymene ocean: The upper Alto Paraguai Group, Paraguay belt, Brazil. Gondwana Research, 21:323-340

Basei M.A.S. \& Brito Neves B.B. 1992. Características geológicas da transição Proterozóico-Faneorozóico no Brasil. In: Gutierrez Marco J.G. \& Rábano I. (eds.) Paleozóico Inferior de Iberoamérica. Mérida, Universidad de Extremadura. p. 331-342.

Boggiani P.C. 1997. Análise estratigráfica da Bacia Corumbá (Neoproterozóico) - Mato Grosso do Sul. Tese de Doutorado, Instituto de Geociências, Universidade de São Paulo, São Paulo, 181 p.

Bouchette F., Seguret M., Moussine-Pouchkine A. 2001. Coarse carbonate breccia as a result of waterwave cyclic loading (Uppermost Jurassic and South-East Basin, France). Sedimentology, 48:767-789.

Cheel R.J. \& Leckie D.A. 1993. Hummocky cross-stratification. Sedimentology Review, 103-122.

Dalziel I.W.D. 1992. On the organization of American plates in the Neoproterozoic and the breakout of Laurentia. GSA Today, 2:240-241

De Raff J.F.M., Boersma J.R., Van Gelder A. 1977. Wave generated structures and sequences from a shallow marine succesion. Lower Carboniferous, County Cork, Ireland. Sedimentology, 4:1-52.

Duke W.L., Arnott R.W.C., Cheel R.J. 1991. Shelf sandstones and hummocky cross- stratification: new insights on a stormy debate. Geology, 19(6):625-628.

Duke W.L. \& Prave A.R. 1992. Storm-and tide-influenced prograding shoreline sequences in the Middle Devonian Mahantango Formation, Pennsylvania. In: Smith D.G., Reison G.E., Zaitlin B.A., Rahmani R.A. (eds.). Clastic Tidal Sedimentology. Canadian Society of Petroleum Geologists, p. 49-370 (Memoir 16).

Dumas S. \& Arnott R.W.C. 2006. Origin of hummocky and swaley cross-stratification - the controlling influence of unidirecional current strength and aggradation rate. Geology, 34(12):1073-1076.

Dunham R.J. 1962. Classification of carbonate rocks according to deposicional texture. In: Ham W.E. (ed). Classification of carbonate rocks. Tulsa: AAPG. p. 108-121 (Memoir, 1)

Figueiredo M.F., Babinski M., Alvarenga C.J.S., Pinho F.E.C. 2008. nova unidade litoestratigráfica registra glaciação ediacarana em Mato Grosso: Formação Serra Azul. Geologia-USP, 8:65-75.

Folk R.L. 1959. Practical petrographic classification of limestones. AAPG Bulletin, 43:1-38.
Folk R.L. 1962. Spectral subdivision of limestone types. In: Ham W.E. (ed). Classification of Carbonate Rocks. Tulsa: AAPG. p. 62-84 (Memoir, 1).

Galloway W.E \& Hobday D.K. 1996. Terrigenous clastic depositional systems: Applications to fossil fuel and groundwater resources. Springer, 16:489

Harms J.C., Southard J.B., Walker R.G. 1982. Structures and sequences in clastic rocks. Society of Economic Paleontologists and Mineralogists, Tulsa, OK, 249 p (Short course, 9 - Lecture Note).

Hidalgo R.L., Petri S., Nogueira A.C.R. 2008. Post-Sturtian and Early Ediacaran microfossils of carbonate sequences in Brazil. In: 26th IAS Meeting of Sedimentology, Bochum.

Hoffman, P.F. \& Schrag, D.P. 2002. The snowball Earth hypothesis: testing the limits of global change. Terra Nova, 14(3):129-155.

Kennedy M.J. 1996. Stratigraphy, sedimentology, and isotopic geochemistry of Australian Neoproterozoic postglacial cap dolostones: deglaciation, $\delta^{13} \mathrm{C}$ excursions, and carbonate precipitation. Journal of Sedimentary Research, 66:1050-1064.

Kerans C. \& Tinker S.W. 1997. Sequence Stratigraphy and characterization of carbonate reservoirs. Society for Sedimentary Geology, Tulsa, 40, SEPM Special Publication, 130 p.

Laznicka P. 1988. Breccias and coarse fragmentites: Petrology. Environments, Associations, Ores. Developments in Economic Geology, 25:842.

Maciel P. 1959. Tilito Cambriano (?) no Estado de Mato Grosso. Boletim da Sociedade Brasileira de Geologia, 8:31-39.

McCrory V.L.C. \& Walker R.G. 1986. A storm- and tidally influenced prograding shoreline - Upper Cretaceous Milk River Formation southern Alberta, Canada. Sedimentology, 33:47-60.

McGee B., Collins A.S., Trindade R.I.F. 2011. G'day Gondwana - the final accretion of a supercontinent: $\mathrm{U}-\mathrm{Pb}$ ages from the post-orogenic São Vicente Granite, northern Paraguay Belt, Brazil, Gondwana Research, 21:316-322

Nogueira A.C.R. 2003. A plataforma carbonática Araras no sudoeste do Cráton Amazônico: estratigrafia, contexto paleoambiental e correlação com os eventos glaciais do Neoproterozóico. Tese de Doutorado, Instituto de Geociências, Universidade de São Paulo, São Paulo, $173 \mathrm{p}$

Nogueira A.C.R., Riccomini C., Sial A.N., Moura C.A.V., Fairchild T.R. 2003. Soft-sediment deformation at the base of the Neoproterozoic Puga cap carbonate (southwestern Amazon craton, Brazil) confirmation of rapid icehouse to greenhouse transition in snowball earth. Geology, 31:613-616.

Nogueira A.C.R. \& Riccomini C. 2006. O Grupo Araras (Neoproterozóico) na parte norte da Faixa Paraguai e sul do Cráton Amazônico, Brasil. Revista Brasileira de Geociências, 36:623-640.

Nogueira A.C.R., Riccomini C., Sial A.N., Moura C.A.V., Trindade R.I.F., Fairchild T.R. 2007. Carbon and Strontium isotope fluctuations and paleoceanographic changes in the late Neoproterozoic Araras carbonate platform, southern Amazon Craton, Brazil. Chemical Geology, 237:168-190

Ramos V.A., Vujovich G., Martino R., Otamendi J. 2010. Pampia: a large cratonic block missing in the Rodinia supercontinent. Journal of Geodynamics, 50:243-255.

Rapela C.W., Pankhurst R.J., Casquet C., Fanning C.M., Baldo E.G., González-Casado J.M., Galindo C., Dahlquist J. 2007. The Río de la Plata craton and the assembly of SW Gondwana. Earth-Science Reviews, 83:49-82. 
Read J.F. 1982. Carbonate platforms of passive (extensional) continental margins: types, characteristics and evolution. Tectonophysics, 81:195-212.

Read J.F. 1985. Carbonate platform facies models Bull. American Association of Petroleum Geologists, 69:1-21.

Ringrose P.S. 1989. Palaeosismic (?) liquefaction event in late Quaternary lake sediment at Glen Roy, Scotland. Terra Nova, 1:57-62.

Rudnitzki I.D. 2011. Fácies e isótopos de carbono e oxigênio da Formação Nobres, Neoproterozóico da Faixa Paraguai Norte, Mato Grosso. Dissertação de Mestrado, Instituto de Geociências, Universidade Federal do Pará, Belém, Pará, 54 p.

Souza E.J. 2012. Tectônica pós-colisional e Estratigrafia da cobertura neoproterozoica-cambriana da Faixa Paraguai Norte, região de Nobres (MT). Dissertação de Mestrado, Instituto de Geociências, Universidade Federal do Pará, Belém, Pará, 65 p.

Tohver E., D’Agrella-Filho M.S., Trindade R.I. 2006. Paleomagnetic record of Africa and South America for the 1200-500Ma interval, and evaluation of Rodinia and Gondwana assemblies. Precambrian Research, 147:193-222.
Tohver E., Trindade R.I.F., Solum J.G., Hall C.M., Riccomini C., Nogueira, A.C. 2010. Closing the Clymene ocean and bending a Brasiliano belt: Evidence for the Cambrian formation of Gondwana, southeast Amazon cráton. Geology, 38:267-270.

Trompette R. 1994. Geology of Western Gondwana (2000-500Ma). Pan-African - Brasiliano aggregation of South America and Africa. Rotterdam, Balkema, 350 p.

Trompette R., Alvarenga C.J.S., Walde D. 1998. Geological evolution of the Neoproterozoic Corumbá graben system (Brazil). Depositional context of the stratified Fe and Mn ores of the Jacadigo Group. Journal of South American Earth Sciences, 11:587-597.

Tucker M. \& Wright V.P. 1990. Carbonate sedimentology. Blackwell Scientific Publications, Oxford, 479 p.

Walker R.G. 1992. Facies, facies models and modern stratigraphic concepts. In: Walker R.G. \& James N.P. (eds) Facies Models- Response to Sea Level Change. Ontario, Geological Association of Canada, p. 1-14.

Wright V.P. 1992. A revised classification of limestones. Sedimentary Geology, 76:177-185.

Arquivo digital disponível on-line no site www.sbgeo.org.br 